\title{
Applying Artificial Intelligence to the Beer Game
}

\section{Dr. Lisa Bosman, Purdue University-Main Campus, West Lafayette (College of Engineering)}

Dr. Bosman has a Ph.D. in Industrial Engineering. Her research interests include Decision Support Systems (e.g., solar energy performance, valuation, and management) and Engineering Education (entrepreneurial mindset, energy education, interdisciplinary education, and faculty professional development). She spent the first part of her career working as a manufacturing engineer for world-class companies including Harley-Davidson, John Deere, and Oshkosh Defense and continues to provide workforce development consulting within this area.

\section{Dr. Aasakiran Madamanchi, Purdue University Polytechnic}

Dr. Madamanchi is an independent Postdoctoral Researcher in the Future Work and Learning strategic impact area of Purdue University Polytechnic. His research centers around supporting digital transformation through workforce development, with a special focus on data science education and AI literacy.

\section{Dr. Scott R Bartholomew, Purdue University at West Lafayette}

Scott R. Bartholomew, PhD. is an assistant professor of Engineering/Technology Teacher Education at Purdue University. Previously he taught Technology and Engineering classes at the middle school and university level. Dr. Bartholomew's current work revolves around Adaptive Comparative Judgment (ACJ) assessment techniques, student design portfolios, and Technology \& Engineering teacher preparation.

\section{Vetria L. Byrd PhD, Purdue University-Main Campus, West Lafayette (College of Engineering)}

Dr. Vetria L. Byrd is an assistant professor in the Department of Computer Graphics Technology in the Polytechnic Institute at Purdue University in West Lafayette, Indiana. Dr. Byrd is the founder and organizer of the biennial Broadening Participation in Visualization (BPViz) Workshop. Dr. Byrd has given numerous invited talks on visualization and has been featured in HPC Wire online magazine (2014), and numerous workshops nationally and internationally. Dr. Byrd received her graduate and undergraduate degrees at the University of Alabama at Birmingham, in Birmingham, Alabama which include: Ph.D. in Computer and Information Sciences, Master's degrees in Computer Science and Biomedical Engineering and a Bachelor's degree in Computer Science. Dr. Byrd's research interests include: data visualization, data visualization capacity building and pedagogy, high performance visualization, big data, collaborative visualization, broadening participation and inclusion. 


\title{
Applying Artificial Intelligence to the Beer Game
}

\author{
Lisa Bosman, Bobby Madamanchi, Scott Bartholomew and Vetria Byrd
}

\section{Introduction}

The U.S. Congress defines big data as "large volumes of high velocity, complex, and variable data that require advanced techniques and technologies to enable the capture, storage, distribution, management and analysis of the information" [1]. Big data and data analytics have the potential to lower costs, improve quality of life, and even save lives by understanding and learning patterns and trends in the recent uptick of incoming data [2]. In response, data science solutions are being increasingly deployed in the business world [3], and the growth of publicly accessible data provides a significant opportunity to transform educational efforts related to data science [4]. Indeed, today's college graduates are expected to have skills in modeling, visualization, and data mining to become successful in the scientific workforce [4]. Unfortunately, recent trends and predictions suggest a critical shortage in the quantity of college graduates prepared to fill this business intelligence demand [3].

In 2016, a group of 25 faculty from across the U.S. met at the Park City Math Institute for the sole purpose to establish guidelines for undergraduate level data science programs and provide structure for the development of new programs [5]. Universities are well aware of the demand issues and have responded with the development of new data science initiatives, such as the University of Notre Dame's recent launch of the new Lucy Family Institute for Data \& Society [6], Purdue University's recent investment in a new $\$ 40$ million facility dedicated to data science research and education, and UC Berkeley's new minor in data science [7].

Yet, gaps still remain. Unless students are majoring, minoring or taking coursework in data science programs specifically, they receive limited experience with big data, machine learning, and artificial intelligence. This is particularly problematic in industrial engineering coursework such as supply chain management (SCM). There is a myriad of opportunities were SCM intersects with artificial intelligence and predictive analytics, however, the literature is sparse with educational opportunities and experiences for integrating artificial intelligence into the supply chain [8]. Although quantitative data related to the inclusion, or lack thereof, of data science training in industrial engineering programs is difficult to obtain, this study was completed in a degree program that does not currently require data science courses.

As we look to develop more T-shaped engineers [9], where students have both a breadth and a depth of knowledge and skills, understanding artificial intelligence applications is extremely important. Artificial intelligence can be applied in many different industrial engineering applications to promote statistical control and improve predictive capabilities. One obvious place to leverage artificial intelligence in the SCM classroom is through freely available games and simulations. The Beer Game is a well-known simulation game widely used within the SCM curriculum [10], and is proven to be very effective and popular across all levels of programs including undergraduate, graduate, and executive education [11]. Developed by MIT's Sloan School of Management in the 80 s, the Beer Game was originally created to teach students systems concepts and systems thinking [12]. However, as the content area of SCM continues to expand, so do the Beer Game learning extensions which now span demonstrating the bullwhip effect, riskpooling, and technology integration, to name a few [13]. In response, student participants get the chance to actively learn about the benefit of supply chain awareness and communication, the 
importance of supply chain collaborative strategic decision making, and the benefit of working as a team to solve problems [14]. The purpose of this study is to report on one approach for integrating artificial intelligence into supply chain education using the well-known beer game (a gamification and simulation approach to learn supply chain principles). Motivation for integrating artificial intelligence into the industrial engineering classroom was driven by the desire to better prepare students to enter the Industry 4.0 and Big Data workforce. The guiding research question was as follows:

- How can artificial intelligence be implemented into an elective engineering course to increase student perceptions and student learning outcomes?

The findings support the effectiveness associated with a 5-week module to improve student perceptions and learning outcomes related to the intersection between supply chain management and artificial intelligence.

\section{Background}

\section{Teaching Artificial Intelligence}

First coined in 1955, the term artificial intelligence (AI) has grown to refer to any computing system which can flexibly and adaptively use external data to achieve specific goals, rather than simply execute pre-programmed computations [15]. Early milestones in AI included the first computing systems that could beat human competitors in games such as Chess and Go [16, 17]. In recent years advances in hardware, and computational approaches have fueled breakthroughs in AI applications such as computer visions and natural language processing $[18,19]$. At the same time businesses are rapidly integrating AI approaches for data-guided decision-making in their existing business operations; a recent survey indicates that the majority ( $\sim 85 \%)$ of large businesses are in the midst of AI implementation plans [20].

Given the greater focus on AI to support decision making, there is a need for industrial engineering students to be prepared to understand and use AI tools in a business context. Yet, at this stage, there is a dearth of educational resources on AI or related technologies that are tailored for this student population [21]. Emerging programs to integrate AI education into industrial engineering curriculum include the development of Industry 4.0 themed labs, both physical [22, 23] and virtual [24]. To date, these efforts tend to be technology-focused with an emphasis on Internet-of-Things applications with limited attention to the AI and data-guided decision making. Outside of industrial engineering education, AI education for engineers is often promoted through extra- or cocurricular avenues including interdisciplinary research [25], service-learning [26]. These approaches often lack a focus on industrial engineering relevant business applications, and also have a limitation on the number of students that they can reach. In recent years a growing number of instructors have begun to teach courses on data science or AI for non-majors [27-29]. Some of these courses feature games [30] or web-apps [31] to make the material more approachable, but there is limited research on the educational outcomes of these efforts.

\section{Introduction to the Beer Game}

The Beer Distribution Game is an educational role-playing exercise which has been a staple of supply chain education for decades $[12,32]$. In the game a simplified four member beer 
distribution supply chain consisting only of a beer factory, beer wholesaler, beer distributor and beer retailer are used to illustrate the importance of information sharing, coordination, and scientific inventory management techniques [12]. Studies have demonstrated that naïve game play, even with total information transparency among participants, results in large, fluctuating disruptions to the supply chain known as the bullwhip effect [33-36].

Over the years a number of educators have developed computer-based [37], phone-based [38], or web-based versions [39-41]. At the same time researchers investigating AI applications in supply chain management have used reinforcement learning approaches to develop algorithmic solutions for playing the beer game while minimizing the bullwhip effects [42, 43]. More recently, OpexAnalytics has published a free online Beer Game that allows individuals to play as humans, as AIs, or in a combination [44]. Although there has been research on the effectiveness of teaching supply chain principles through the Beer Game, there is no research available on the effectiveness of teaching AI or data-guided decision-making to industrial engineering students using the Beer Game.

\section{Methods}

\section{Participants and Research Design}

Participants included 120 sophomore-level students, enrolled in a three-credit course called Supply Chain Management Technology, at a research-intensive university in the Midwest United States. The course is required for students enrolled in the Industrial Engineering Technology (IET) bachelor's degree program, and also serves as an elective for non-IET majors. The course description includes topics such as supply chain design, supply chain strategy, supply chain process mapping, and supply chain decision making with the use of technology, data analysis, and performance metrics. Participants completed a 5-week teaching invention including five key learning experiences, as summarized in Figure 1. This five-week module included three weeks of the free traditional classic online beer game (Figure 2) and 2 weeks of the free online artificial intelligence-enhanced beer game (Figure 3).
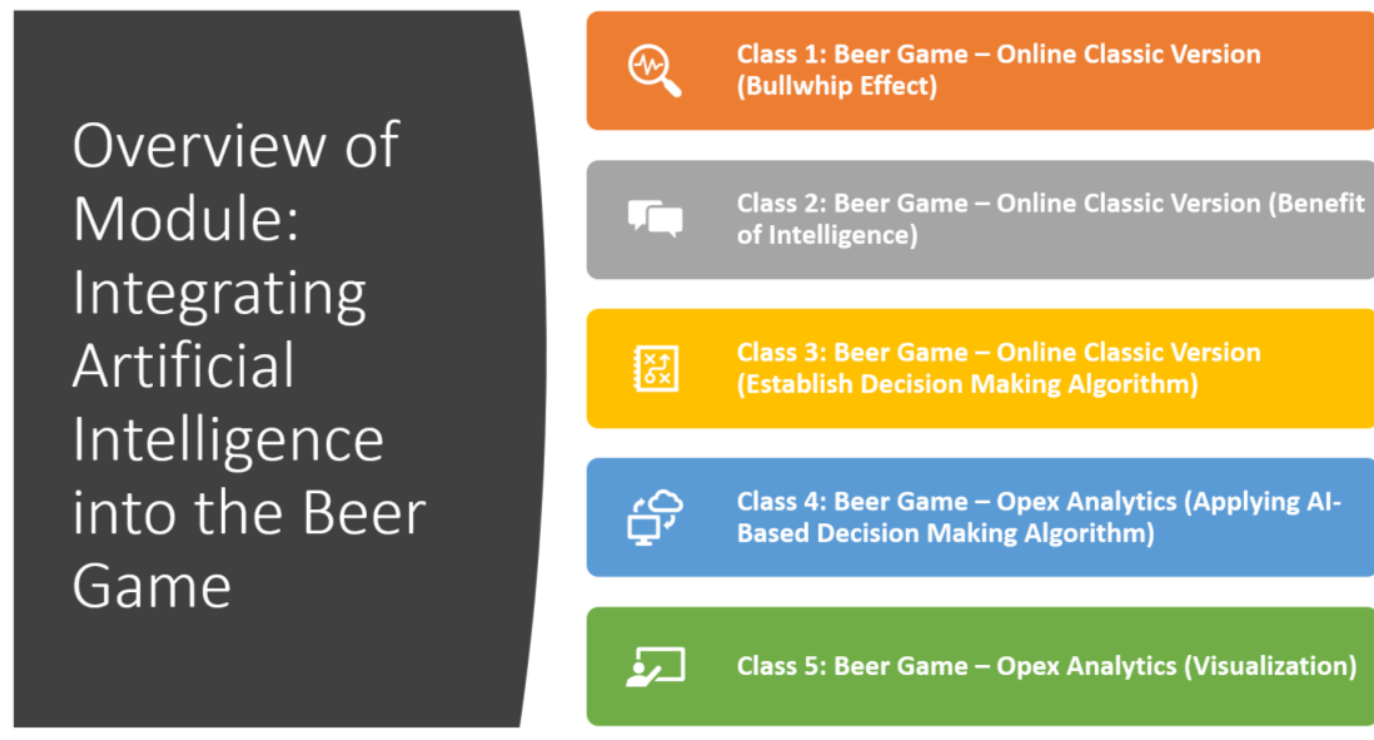

Class 4: Beer Game - Opex Analytics (Applying AlBased Decision Making Algorithm)

\section{Class 5: Beer Game - Opex Analytics (Visualization)}

Figure 1: Summary of 5 Key Learning Experiences 


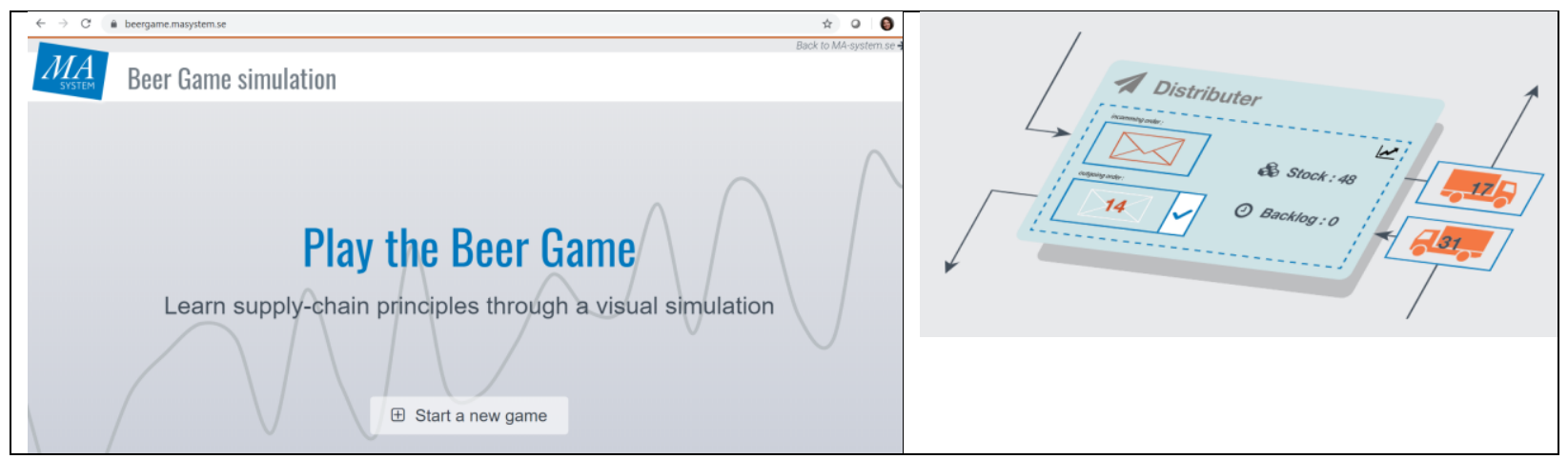

Figure 2: Screen Shots for Classic Beer Game (beergame.masystem.se)

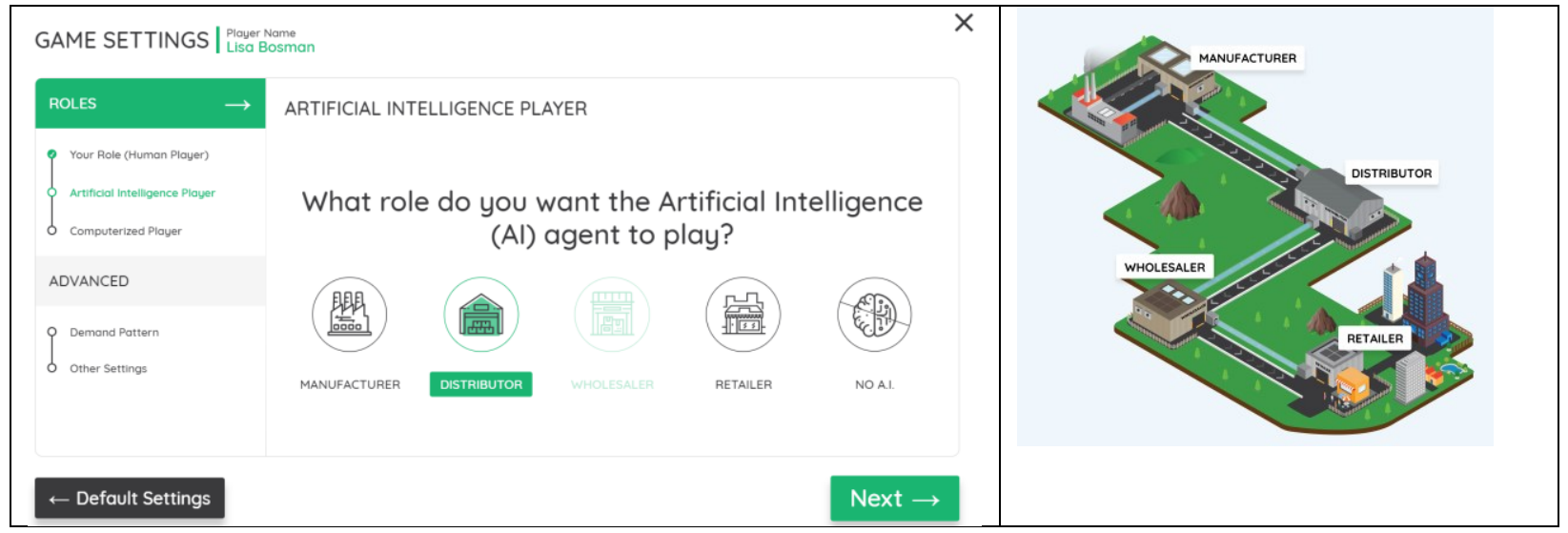

Figure 3: Screen Shots for Opex Analytics AI Beer Game (beergame.opexanalytics.com)

First, students received a short lecture and then participated in the beer game during each weekly 50-minute face-to-face session. This allowed them to receive a practical applied understanding of the concepts for the first time.

Second, students completed an assignment outside the classroom which required posting weekly to a discussion section [45-47]. Each discussion required an initial post and response to two peers' posts. See Appendix A for discussion prompts. The discussion prompts promoted repetition in learning in that they allowed students to apply practical understanding for the second time. To increase a sense of community, discussion groups were limited to 30 students, which resulted in a total of four discussion groups. In addition, in preparation for the team-based project (4 students per team), one person from each time was assigned to each discussion group. This modified approach to the Jigsaw method [48] allowed students to gain a more wholistic perspective (of the entire class) in preparation for the team-based project.

Third, this module culminated with a final team-based project. This final module project promoted repetition in learning in that it allowed students to apply practical understanding for the third time. See Appendix B for project requirements.

\section{Data Collection and Data Analysis}

Two sets of data were collected to assess the research questions. First, prior to the start of the module, students completed PRE open-ended questions (shown below). Second, at the end of the module, students responded to the same POST open-ended questions. The open-ended questions will be analyzed qualitatively through thematic analysis to understand potential themes in the data. 
According to Braun and Clark [49], a thematic analysis is a foundational qualitative method for discovering patterns within the data. It should be conducted using a step by step process. The researchers first became thoroughly familiar with the data to generate initial codes. Upon the completion of coding, themes were generated. As a final step, the researchers revised the themes and wrote the report. Quotes, which provide evidence of the themes, were drawn from the data to allow readers to make their own judgements on credibility, accuracy, and fairness [50].

1. What is artificial intelligence?

2. Can you list an example application of artificial intelligence?

3. Can you list an example specific to supply chain management?

\section{Results and Discussion}

In general, while comparing all three PRE vs. POST responses, the PRE responses included a large quantity of "I don't know" to respond to the three questions, whereas, the POST responses all provided an answer. This section will provide an overview of responses broken out by question.

\section{PRE vs. POST: What is artificial intelligence?}

A summary of responses to What is artificial intelligence? is provided in Table 1. In general, for PRE responses, students provided explanations of artificial intelligence related to that of robots or automated technology. In many cases, responses regarded artificial intelligence as a black box, magical mystery machine which can do work without the help of humans. For POST responses, on the other hand, students tended to provide more sophisticated responses. The change in responses from simplistic to sophisticated suggests an increase in student learning towards better understanding capabilities of artificial intelligence.

Table 1: Summary of Responses - What is artificial intelligence?

\begin{tabular}{|c|c|}
\hline \multicolumn{2}{|l|}{ 1. What is artificial intelligence? } \\
\hline PRE & POST \\
\hline $\begin{array}{l}\text { "Artificial intelligence is technology having a } \\
\text { conscious mind of their own." } \\
\text { "Artificial intelligence means that things are } \\
\text { able to think on their own." } \\
\text { "When I think of AI, I think of robots that do a } \\
\text { particular function." } \\
\text { "Artificial Intelligence is technology that can } \\
\text { make independent decisions." } \\
\text { "Artificial Intelligence is an electronic tool } \\
\text { used in the work force." } \\
\text { "Any sort of computer assisted program that } \\
\text { can perform a higher level task." } \\
\text { "Man-made computer controlled robots that } \\
\text { can replace more and more common jobs." }\end{array}$ & $\begin{array}{l}\text { "Artificial intelligence is intelligence that is } \\
\text { recreated by machine to run diagnostics on } \\
\text { data to interpret trends and correctly analyze } \\
\text { that." } \\
\text { "Artificial intelligence is a learning algorithm } \\
\text { that can process and analyze data for the } \\
\text { purpose of creating a forecast." } \\
\text { "Artificial Intelligence is the use of technology } \\
\text { to see patterns and make work easier." } \\
\text { "Artificial intelligence is the use of computer } \\
\text { science and data interpretation to complete a } \\
\text { task." } \\
\text { "AI is using computer programs to analyze } \\
\text { data, identify trends and develop algorithms to } \\
\text { make decisions." }\end{array}$ \\
\hline
\end{tabular}


PRE vs. POST: Can you list an example application of artificial intelligence?

A summary of responses to Can you list an example application of artificial intelligence? is provided in Table 2. In general, for PRE responses, students provided examples of artificial intelligence applications that centered around robotics, automation and sensing. The responses tended to be short and simply with little explanation. For POST responses, on the other hand, students tended to provide more sophisticated responses with a greater focus on the use of data analytics and big data. The change in responses from a narrowed view of automation to a more holistic view integrating big data suggests an increase in student learning towards better understanding capabilities of artificial intelligence.

Table 2: Summary of Responses - Can you list an example application of artificial intelligence?

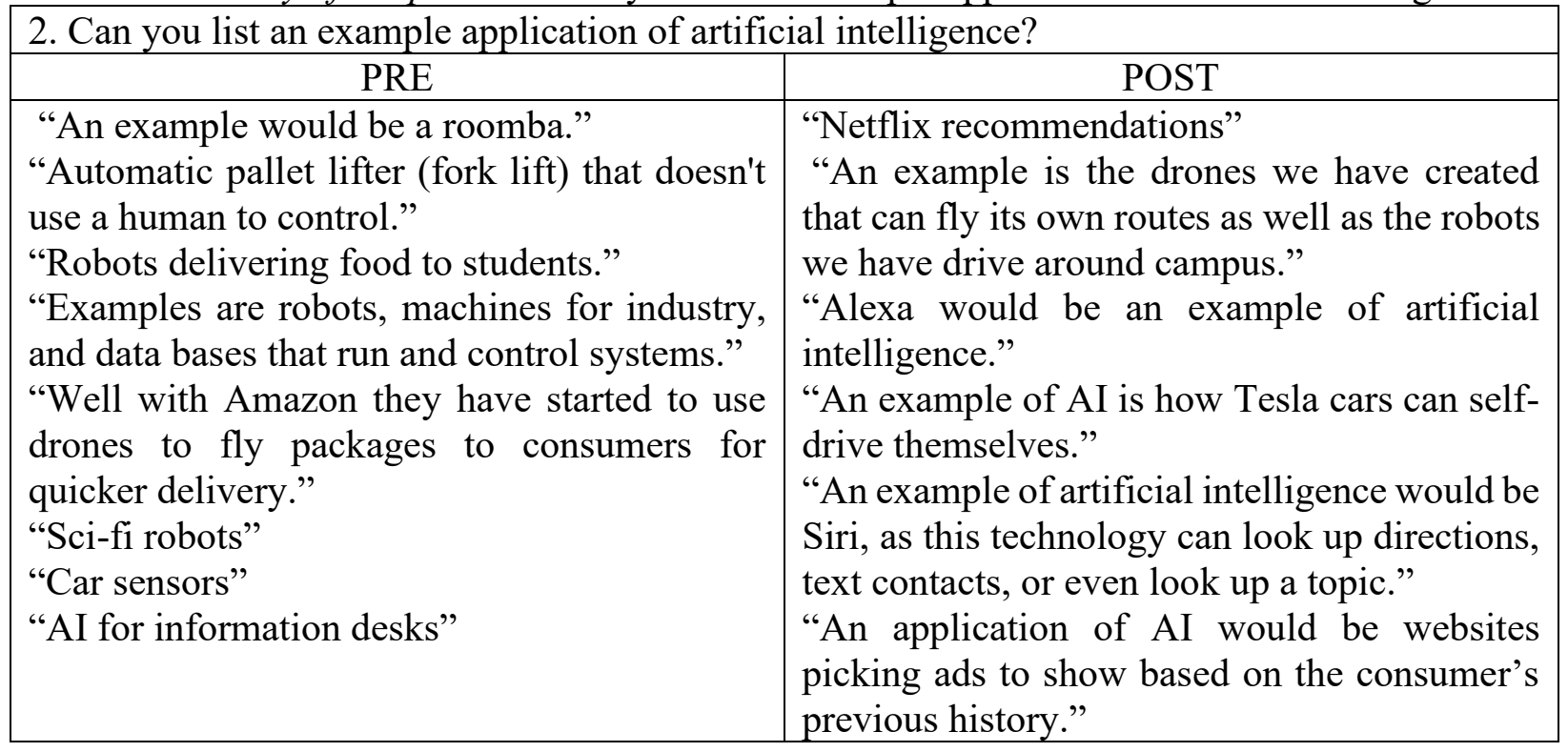

PRE vs. POST: Can you list an example specific to supply chain management?

A summary of responses to Can you list an example specific to supply chain management? is provided in Table 3 . In general, for PRE responses, students provided extremely vague examples of applications and benefits specific to supply chain management. The responses tended to be short and simple with little explanation. For POST responses, on the other hand, students tended to provide more sophisticated responses with a greater focus on actual ways to apply and benefit from the integration of artificial intelligence in supply chain management. The change in responses from a limited and vague perspective to a more utilitarian and inclusive perspective suggests an increase in student learning towards better understanding capabilities of artificial intelligence. 
Table 3: Summary of Responses - Can you list an example specific to supply chain management?

\begin{tabular}{|c|c|}
\hline \multicolumn{2}{|l|}{ xample } \\
\hline PRE & POST \\
\hline $\begin{array}{l}\text { used in supply chain management } \\
\text { djustments for the business if } \\
\text { cur." } \\
\text { be able to ask the computer to do } \\
\text { otential scenarios." } \\
\text { chain management, they use AI to } \\
\text { any unnecessary costs." } \\
\text { chain management, artificial } \\
\text { helps to identify and sort the } \\
\text { received from the customers." } \\
\text { ntelligence can be used in supply } \\
\text { gement through tasks such as } \\
\text { nanufacturing." } \\
\text { the data, and create actionable } \\
\text { supply chain managers." } \\
\text { intelligence is used in a supply } \\
\text { ms of gathering data as well as } \\
\text { w information." } \\
\text { ain uses it to create efficiency } \\
\text { chain." }\end{array}$ & $\begin{array}{l}\text { shipment." } \\
\text { "AI can be used } \\
\text { in shipments a } \\
\text { storage for comp } \\
\text { "Artificial intelli } \\
\text { management } \\
\text { interpreting tren } \\
\text { be able to calcula } \\
\text { "Artificial intelli } \\
\text { management to } 1 \\
\text { by reacting to } \\
\text { predicting future } \\
\text { inventory level c } \\
\text { with human int } \\
\text { decisions to bene } \\
\text { "AI can be us } \\
\text { functions like } \\
\text { procurement de }\end{array}$ \\
\hline
\end{tabular}

\section{Conclusions}

The purpose of this study is to provide one approach for integrating artificial intelligence into supply chain education using the well-known beer game (a gamification and simulation approach to learn supply chain principles). Motivation for integrating artificial intelligence into the industrial engineering classroom is driven by the desire to better prepare students to enter the Industry 4.0 and big data workforce. Findings provide evidence towards the effectiveness of the 5-week module to improve student perceptions and learning outcomes related to the intersection between supply chain management and artificial intelligence. It is not intended for this module to sufficiently prepare students for data science and artificial intelligence work assignments; yet, this module offers a starting point for further skill development in high level coursework. 


\title{
Appendix A: Discussion Prompts for AI-Focused Beer Game Module
}

\author{
Week 1: Bullwhip Effect
}

Initial Post: Create an infographic to explain and demonstrate the bullwhip effect. Check out this video if you are looking for more info on the bullwhip effect. The infographic should include data from playing the beer game. Post the infographic as a PDF (8.5" x 11") to Blackboard. Be sure your name is NOT included in the infographic. In the text box, identify what software you used to create the infographic.

Response Post: Respond to a minimum of two peers' posts (with the least amount of responses) responding to the following questions: (1) What advice do you have for your peer on how to prevent the bullwhip effect from occurring? (2) Identify one thing you like most about the infographic. (3) Identify one opportunity for improvement on the infographic.

\section{Week 2: Benefit of Intelligence}

Initial Post: Create an infographic to explain and demonstrate the benefit of intelligence. Check out this video to learn more about the benefit of intelligence. The infographic should include data from playing the beer game, comparing this week's data (with intelligence) to last week's data (without intelligence). Post the infographic as a PDF (8.5" $\mathrm{x} 11$ ") to Blackboard. Be sure your name is NOT included in the infographic. In the text box, explain how you used supply chain intelligence to inform your purchasing decision making.

Response Post: Respond to a minimum of two peers' posts (with the least amount of responses) responding to the following questions: (1) How does your use of intelligence compare and contrast to your peer's use of intelligence? (2) Identify one thing you like most about the infographic. (3) Identify one opportunity for improvement on the infographic.

\section{Week 3: Decision Making Algorithm}

Initial Post: Create an infographic to explain and demonstrate your decision making algorithm. Check out these resources (Website 1 and Website 2) to learn more about creating decision making algorithms. The infographic should include data from playing the beer game, comparing this week's data (with intelligence) to last week's data (without intelligence). Post the infographic as a PDF (8.5" $x 11$ ") to Blackboard. Be sure your name is NOT included in the infographic. In the text box, explain the process of how you discovered the logic for your decision-making algorithm.

Response Post: Respond to a minimum of two peers' posts (with the least amount of responses) responding to the following questions: (1) How does your decision-making algorithm compare and contrast to your peer's? (2) Identify one thing you like most about the infographic. (3) Identify one opportunity for improvement on the infographic.

\section{Week 4: AI-Based Decision Making Algorithm}

Initial Post: Create an infographic to explain and demonstrate the benefit of artificial intelligence (AI) to minimize the bullwhip effect. The infographic should incorporate the "Inventory Level vs Time" graph from the Opex Analytics Beer Game. Check out these resources (anva 1 and Canva 
2) for more information. The infographic should be made using Canva. Post the infographic as a PDF (8.5" x 11") to Blackboard. Be sure your name is NOT included in the infographic. In the text box, explain the intended finding, conclusion, and/or overarching takeaway message.

Response Post: Respond to a minimum of two peers' posts (with the least amount of responses) responding to the following questions: (1) Identify one thing you like most about the infographic. (2) Identify one opportunity for improvement on the infographic.

\section{Week 5: Data Visualization}

Initial Post: Create an infographic to explain and demonstrate the benefit of artificial intelligence (AI) to minimize the bullwhip effect, which also follows the Visualization checklist (see Blackboard for checklist and 10/30/19 lecture with detailed explanations). The infographic should use data downloaded from the Opex Analytics Beer Game (see Blackboard for 10/23/19 handout to obtain data. The infographic should be made using Canva. Post the infographic as a PDF (8.5" x 11") to Blackboard. Be sure your name is NOT included in the infographic. In the text box, explain the intended finding, conclusion, and/or overarching takeaway message.

Response Post: Respond to a minimum of two peers' posts (with the least amount of responses) responding to the following questions: (1) Identify one thing you like most about the infographic, responding specifically to the Visualization checklist. (2) Identify one opportunity for improvement on the infographic, responding specifically to the Visualization checklist.

\section{Appendix B: Team-Based Project Requirements}

Team Part (50\% of Project 2 Grade):

- Cover Page (1 page)

- Names of each of the team members, Course name and number, Date

- How is artificial intelligence (AI) used in the supply chain context? (1 page)

- What are the benefits of AI in the supply chain context? (1 page)

- What are the challenges of AI in the supply chain context? (1 page)

- How can a supply chain professional be better prepared / trained for using AI in the supply chain context? (1 page)

- Works Cited (1 page)

Individual Part (50\% of grade):

- Create an infographic using Canva (8.5" x 11", uploaded as a PDF) which follows the Visualization checklist.

- The infographic should summarize lessons learned and key takeaways from each week of Module 2: (1) Bullwhip Effect, (2) Benefit of Intelligence, (3) Establishing a Decision Making Algorithm, (4) Applying an AI-Based Decision Making Algorithm, and (5) Data Visualization.

- The infographic must incorporate at least one example of data visualization (created by you, using the Visualization checklist as a guide). 
Individual Part - Example:

\section{THE BEER GAME: LESSONS LEARNED \& KEY TAKEAWAYS}

\section{WHAT IS THE BULLWHIP EFFECT?}

The Bullwhip Effect is the phenomenon of increased inventory as a result of increased consumer demand as one moves up the supply chain, just as the height of a whip increases the further down the whip you go. It often results in supply chain inefficiencies and can be very costly.

\section{WHAT IS INTELLIGENCE IN A SUPPLY CHAIN?}

Intelligence in a supply chain is the communication between, systematic understanding, and quantitative data to support and understand each component in the supply chain.

\section{ESTABLISHING \& APPLYING AN AIALGORITHM.}

\section{WHAT IS ARTIFICIAL INTELLIGENCE?}

$\mathrm{Al}$ is the process of using computer systems to perform tasks and make decisions that typically would require human intelligence (learning, problem solving, etc.)

\section{WITH AI ALGORITHM}

- more consistent orders

- backlog remained $<5$

- more consistent costs

\section{WITHOUT AI ALGORITHM}

- orders not consistent with demand

- backlog was very high

- costs fluctuated greatly

\section{CHANGE IN INVENTORY QUANTITIES USING AI.}

Artificial intelligence at the distributor level allows for better forecasting accuracy keeping ending inventory levels within +/- 5 for all components of the supply chain, thus minimizing the bullwhip.

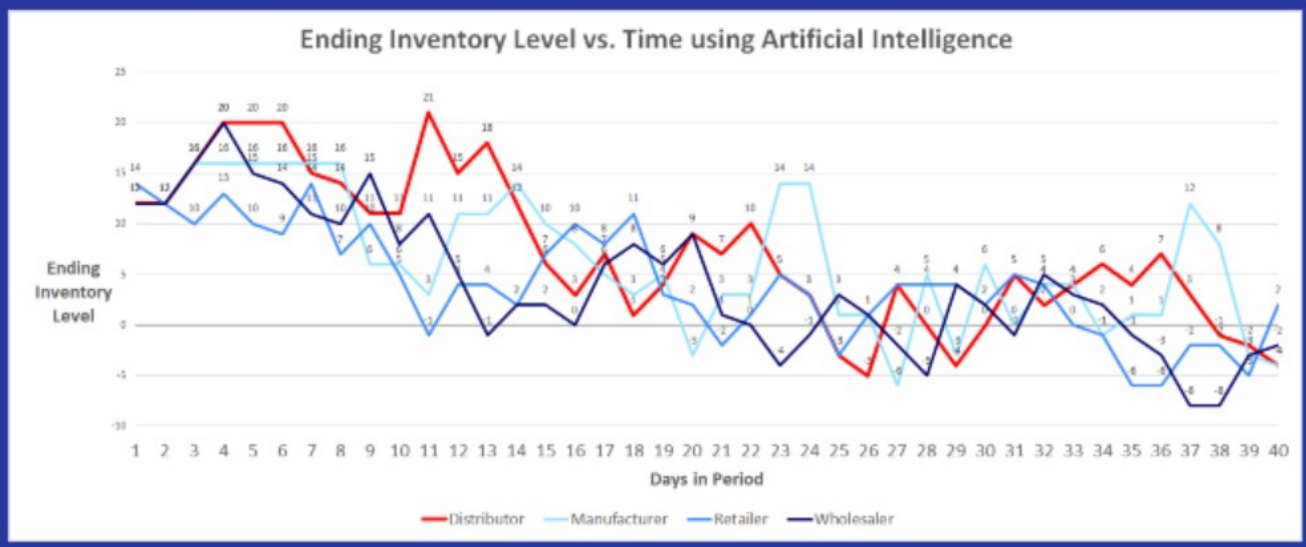




\section{References}

[1] M. Cottle, W. Hoover, S. Kanwal, M. Kohn, T. Strome, and N. Treister, "Transforming Health Care Through Big Data Strategies for leveraging big data in the health care industry," Institute for Health Technology Transformation, http://ihealthtran. com/bigdata-in-healthcare, 2013.

[2] W. Raghupathi and V. Raghupathi, "Big data analytics in healthcare: promise and potential," Health Information Science and Systems, vol. 2, p. 3, 2014/02/07 2014.

[3] B. Gupta, M. Goul, and B. Dinter, "Business Intelligence and Big Data in Higher Education: Status of a Multi-Year Model Curriculum Development Effort for Business School Undergraduates, MS Graduates, and MBAs," CAIS, vol. 36, p. 23, 2015.

[4] S. Donovan, "Big data: teaching must evolve to keep up with advances," Nature, vol. 455, pp. 461-461, 2008/09/01 2008.

[5] R. D. De Veaux, M. Agarwal, M. Averett, B. S. Baumer, A. Bray, T. C. Bressoud, L. Bryant, L. Z. Cheng, A. Francis, and R. Gould, "Curriculum guidelines for undergraduate programs in data science," Annual Review of Statistics and Its Application, vol. 4, pp. 1530, 2017.

[6] P. Gibbons. (2019) Notre Dame launches new Lucy Family Institute for Data \& Society. Notre Dame News. Online retrieved 12/25/2019: https:/news.nd.edu/news/notre-damelaunches-new-lucy-family-institute-for-data-society/.

[7] UCBerkeley, "Data Science Minor. Online retrieved 12/25/2019: https://data.berkeley.edu/academics/undergraduate-programs/data-science-minor," 2019.

[8] M. A. Waller and S. E. Fawcett, "Data Science, Predictive Analytics, and Big Data: A Revolution That Will Transform Supply Chain Design and Management," Journal of Business Logistics, vol. 34, pp. 77-84, 2013.

[9] T. Brown, Change by design: how design thinking transforms organizations and inspires innovation New York, NY: Harper Collins, 2009.

[10] A. K. W. Lau, "Teaching supply chain management using a modified beer game: an action learning approach," International Journal of Logistics Research and Applications, vol. 18, pp. 62-81, 2015/01/02 2015.

[11] D. Sparling, "Simulations and supply chains: strategies for teaching supply chain management," Supply Chain Management: An International Journal, vol. 7, pp. 334-342, 2002.

[12] J. S. Goodwin and S. G. Franklin, "The beer distribution game: using simulation to teach systems thinking," Journal of Management Development, vol. 13, pp. 7-15, 1994.

[13] P. M. Reyes, "Parallel interaction supply chain game: An extension of the beer game," Decision Sciences Journal of Innovative Education, vol. 5, pp. 413-421, 2007.

[14] L. Zhou, Y. Xie, N. Wild, and C. Hunt, "Learning and practising supply chain management strategies from a business simulation game: a comprehensive supply chain simulation," in Proceedings of the 40th Conference on Winter Simulation, 2008, pp. 2534-2542.

[15] A. Kaplan and M. Haenlein, "Siri, Siri, in my hand: Who's the fairest in the land? On the interpretations, illustrations, and implications of artificial intelligence," Business Horizons, vol. 62, pp. 15-25, 2019.

[16] E. Gibney, "Google AI algorithm masters ancient game of Go," Nature News, vol. 529, p. 445, 2016.

[17] D. Hassabis, "Artificial Intelligence: Chess match of the century," Nature, vol. 544, p. 413, 2017. 
[18] N. Jones, "Computer science: The learning machines," Nature News, vol. 505, p. 146, 2014.

[19] G. Goth, "Deep or shallow, NLP is breaking out," Communications of the ACM, vol. 59, pp. 13-16, 2016.

[20] J. K.-U. Brock and F. Von Wangenheim, "Demystifying AI: What Digital Transformation Leaders Can Teach You about Realistic Artificial Intelligence," California Management Review, vol. 61, pp. 110-134, 2019.

[21] S. M. Sackey and A. Bester, "Industrial engineering curriculum in Industry 4.0 in a South African context," South African Journal of Industrial Engineering, vol. 27, pp. 101-114, 2016.

[22] S. M. Sackey, A. Bester, and D. Adams, "Industry 4.0 learning factory didactic design parameters for industrial engineering education in South Africa," South African Journal of Industrial Engineering, vol. 28, pp. 114-124, 2017.

[23] M. D. Prieto, Á. F. Sobrino, L. R. Soto, D. Romero, P. F. Biosca, and L. R. Martínez, "Active Learning based Laboratory towards Engineering Education 4.0," in 2019 24th IEEE International Conference on Emerging Technologies and Factory Automation (ETFA), 2019, pp. 776-783.

[24] M. Stefanovic, "The objectives, architectures and effects of distance learning laboratories for industrial engineering education," Computers \& Education, vol. 69, pp. 250-262, 2013.

[25] N. Merchant and H. H. Zhang, "UA Institutes Work to Build Data Literacy and Transdisciplinary Research," 2018.

[26] M. Phillips and M. R. Jahanshahi, "Integrating data information literacy into a servicelearning engineering design course," in 2017 IEEE Frontiers in Education Conference (FIE), 2017, pp. 1-5.

[27] M. Guzdial, "A media computation course for non-majors," in ACM SIGCSE Bulletin, 2003, pp. 104-108.

[28] Y. Gil, "Teaching parallelism without programming: a data science curriculum for non-CS students," in 2014 Workshop on Education for High Performance Computing, 2014, pp. $42-48$.

[29] H.-T. Lin, M. Madgon-Ismail, and Y. S. Abu-Mostafa, "Teaching machine learning to a diverse audience: the foundation-based approach," in Teaching Machine Learning Workshop at the 25th International Conference on Machine Learning (ICML), 2012.

[30] S. A. Wallace, R. McCartney, and I. Russell, "Games and machine learning: a powerful combination in an artificial intelligence course," Computer Science Education, vol. 20, pp. 17-36, 2010.

[31] J. Li, "Experience Report: Explorable Web Apps to Teach AI to Non-Majors," The Journal of Computing Sciences in Colleges, p. 128, 2019.

[32] F. Pasin and H. Giroux, "The impact of a simulation game on operations management education," Computers \& Education, vol. 57, pp. 1240-1254, 2011.

[33] J. Nienhaus, A. Ziegenbein, and P. Schönsleben, "How human behaviour amplifies the bullwhip effect. A study based on the beer distribution game online," Production Planning \& Control, vol. 17, pp. 547-557, 2006.

[34] H. L. Lee, V. Padmanabhan, and S. Whang, "The bullwhip effect in supply chains," Sloan management review, vol. 38, pp. 93-102, 1997.

[35] M. Coppini, C. Rossignoli, T. Rossi, and F. Strozzi, "Bullwhip effect and inventory oscillations analysis using the beer game model," International journal of production Research, vol. 48, pp. 3943-3956, 2010. 
[36] J. D. Sterman, "Modeling managerial behavior: Misperceptions of feedback in a dynamic decision making experiment," Management science, vol. 35, pp. 321-339, 1989.

[37] J. R. Coakley, J. A. Drexler Jr, E. W. Larson, and A. E. Kircher, "Using a computer-based version of the beer game: Lessons learned," Journal of Management Education, vol. 22, pp. 416-424, 1998.

[38] J. M. Day and M. Kumar, "Using SMS text messaging to create individualized and interactive experiences in large classes: A beer game example," Decision Sciences Journal of Innovative Education, vol. 8, pp. 129-136, 2010.

[39] S. Sarkar and S. Kumar, "Demonstrating the effect of supply chain disruptions through an online beer distribution game," Decision Sciences Journal of Innovative Education, vol. 14, pp. 25-35, 2016.

[40] J. A. Machuca and R. del Pozo Barajas, "A computerized network version of the Beer Game via the Internet," System Dynamics Review: The Journal of the System Dynamics Society, vol. 13, pp. 323-340, 1997.

[41] F. R. Jacobs, "Playing the beer distribution game over the internet," Production and Operations Management, vol. 9, pp. 31-39, 2000.

[42] A. Oroojlooyjadid, M. Nazari, L. Snyder, and M. Takáč, "A Deep Q-Network for the Beer Game: A Reinforcement Learning Algorithm to Solve Inventory Optimization Problems," arXiv preprint arXiv:1708.05924, 2017.

[43] S. K. Chaharsooghi, J. Heydari, and S. H. Zegordi, "A reinforcement learning model for supply chain ordering management: An application to the beer game," Decision Support Systems, vol. 45, pp. 949-959, 2008.

[44] O. Analytics, "5 Reasons We Created the Opex Analytics Beer Game," in Opex-Analytics, ed: @opexanalytics, 2019.

[45] L. Bosman and S. Fernhaber, "Applying Authentic Learning through Cultivation of the Entrepreneurial Mindset in the Engineering Classroom," Education Sciences, vol. 9, p. 7, 2019.

[46] L. Bosman, B. Mayer, and P. McNamara, "Promoting entreprenuerially minded learning through online discussions - curriculum innovation: incorporating the Kern Engineering Entrepreneurial Network (KEEN) framework into online discussions," in American Society of Engineering Education, Columbus, OH, 2017.

[47] L. B. Bosman, N. Duval-Couetil, B. Mayer, and P. McNamara, "Using Online Discussions to Develop the Entrepreneurial Mindset in Environmental Engineering Undergraduates: A Case Study," International Journal of Engineering Pedagogy, vol. 9, 2019.

[48] C.-C. Chang, "Using jigsaw collaborative learning strategy in online discussion to foster a project-based learning community on the web," International Journal of Instructional Media, vol. 36, pp. 221-234, 2009.

[49] V. Braun and V. Clarke, "Using thematic analysis in psychology," Qualitative research in psychology, vol. 3, pp. 77-101, 2006.

[50] A. Corden and R. Sainsbury, Using verbatim quotations in reporting qualitative social research: researchers' views: University of York York, 2006. 